\title{
Construction of A County Level's Water System Restoration Framework Based on Ecological Wisdom:
}

\author{
A Case of Weiyuan
}

Jiacheng Li, Chongqing University, China

\begin{abstract}
Under the background of the construction of ecological civilization in the new era and the initial establishment of land and space planning, ecological spatial planning moves from background to foreground in the context of spatial planning system, and the water system is an important factor in the series of ecological elements. How to maintain the river ecological characteristics without degradation is an important link in regional comprehensive management and ecological transformation. It is also the key to improve the resilience of regional ecosystems. In view of the lack of clarity in the research scale of water system ecological restoration and the lack of exploration of natural hydrological cycle mechanism, this paper introduces the concept of ecological wisdom to explore the framework of water restoration, emphasizing the protection, restoration and learning simulation of water cycle mechanism. On this basis, combined with the practice of ecological restoration in Weiyuan County, Sichuan Province, the concept of ecological wisdom is used to learn to simulate the natural water cycle mechanism, and the water body restoration framework is discussed from the cycle process in order to provide a certain reference for related practices.
\end{abstract}

\section{Keywords}

ecological wisdom, county level, natural water cycle mechanism, water system restoration

\section{Introduction}

Water is the source of life, and human beings are naturally hydrophilic. The ancestors lived by the water and built on the water. The meaning of the water system has gone beyond the scope of life support and transportation, while pursuing an artistic conception of "the setting sun goes to the water and surrounds the tower". Today, the water system carries the profound connotation of ecology and culture, but it is also generally faced with the dilemma of "water loss" and "water control". At present, urban development is transforming from the extensive development of "incremental expansion" to the intensive development of "exploiting the potential of stock", from emphasizing "protection" and "ecology priority" to using ecological catalysts to guide and activate regional development, . In the context of the construction of ecological civilization in the new era and the preliminary establishment of territorial and spatial planning, creating an inclusive, healthy and sustainable spatial ecological environment has become an important issue in the new era. "The best doctors treat diseases that have not yet appeared, middle-level doctors treat upcoming diseases, and lower-level doctors treat diseases that have already begun", Water as an important carrier of urban history, culture and ecosystem services is an important factor of urban spatial form tissue formation, but also the region most development potential and vitality of the city. Using the concept of ecological wisdom to understand the ecological laws of the water system 
is of great significance for improving the resilience of the water system and promoting the construction of regional ecological civilization.

At present, domestic related researches are mostly concentrated in urban built-up areas, and there is relatively little exploration of a regional water system restoration framework. Sorting out the construction ideas of the regional water analysis strategy has certain significance for water space restoration under the background of land space.Therefore, this article takes Weiyuan County as an example, discusses the water body restoration framework based on the concept of ecological wisdom, and explores a whole-region water body space restoration framework, hoping to provide a certain reference for related practices.

\section{Regional water system restoration framework under ecological wisdom}

\subsection{An important idea for urban ecological restoration: Ecological wisdom}

Ecological wisdom originates from adapting to the environment. It advocates respect, protection and conformity to nature. It is the sum of various survival strategies and survival concepts that can make the environment more suitable for survival formed by the long-term interaction of living organisms with the environment. It is persistence Under the premise of conforming to nature and protecting nature, we should rationally use nature, transform nature, and make maximum use of it while minimizing risks. We use word formation to analyze "ecological wisdom". Ecological wisdom is a dual concept that includes the core features of natural ecology and the core features of human wisdom. The wisdom here has two meanings. One is the wisdom of nature, just like bionics, imitating creatures in nature and designing and manufacturing, as Jenny Benas said, "We live on a smart planet, and we are surrounded by geniuses.". The second is human wisdom, that is, smart countermeasures, which means that humans make full use of their own wisdom, skills, and methods to rationally analyze and simulate ecological processes, so as to achieve the results of seeking advantages and avoiding disadvantages and turning disadvantages into benefits. The two complement each other. The introduction of ecological wisdom theory in urban ecological restoration planning can help cities form an "ecological self-discipline system", realize the process of self-response, self-regulation, self-recovery, and self-improvement, and maintain the city for a long time without using or using very little external force. Wisdom and ecological characteristics are not degraded.

\subsection{Construction of a global ecological restoration framework based on ecological wisdom}

Regional water body restoration should be based on the current understanding and assessment of the natural background, clarify the water cycle mechanism while mining natural resource endowments, identify ecological spatial characteristics, evaluate potential risks, and discover its unsolved problems. The assessment of the current water environment should start with field investigations, digital elevation models, GIS analysis, and remote sensing analysis models. It is composed of county hydrological pattern, water quality pattern, water quantity pattern, and water landscape pattern. It is through the analysis of river basin flow direction, water source analysis, rain and flood analysis, and soil erosion sensitivity. Through flow direction analysis, water source analysis, rain flood analysis,sensitivity analysis of soil erosion,water quality analysis,biodiversity analysis,shoreline analysis and other series of analyses, combined with the city's topography and existing planning to establish a city-specific water area database. Based on the urban waters database, the water body restoration target can be locked, which can be specifically focused on four aspects: hydrology, water volume, water quantity, and waterscape.

Based on the urban waters database, the water body restoration target can be locked, which can be specifically focused on four aspects: hydrology, water volume, water quantity, and waterscape. The 
rationality of the regional hydrological structure determines the regional water cycle process, and to a certain extent promotes the improvement of regional water quality and water volume. Water volume and water quality are closely related to the quality of waterscape construction. The rationality and stability of the four provide high-quality ecological services for water bodies.

The key to water restoration is to simulate and study the internal mechanisms and laws of natural ecosystems, energy conversion and metabolic processes, and the focus is on the control of the source, process and end of the water cycle. This paper comprehensively summarizes the characteristics of water body structure, builds a water area database, combines the ecological restoration pattern of the water body, simulates the hydrological cycle process, proposes four pattern goals of hydrology, water volume, water quality, and waterscape, and constructs spatial pattern system optimization, water cycle process simulation, and multiple waterscape creation The overall resilience improvement strategy of the water system is provided, and the corresponding construction project library is given(Figure 1).

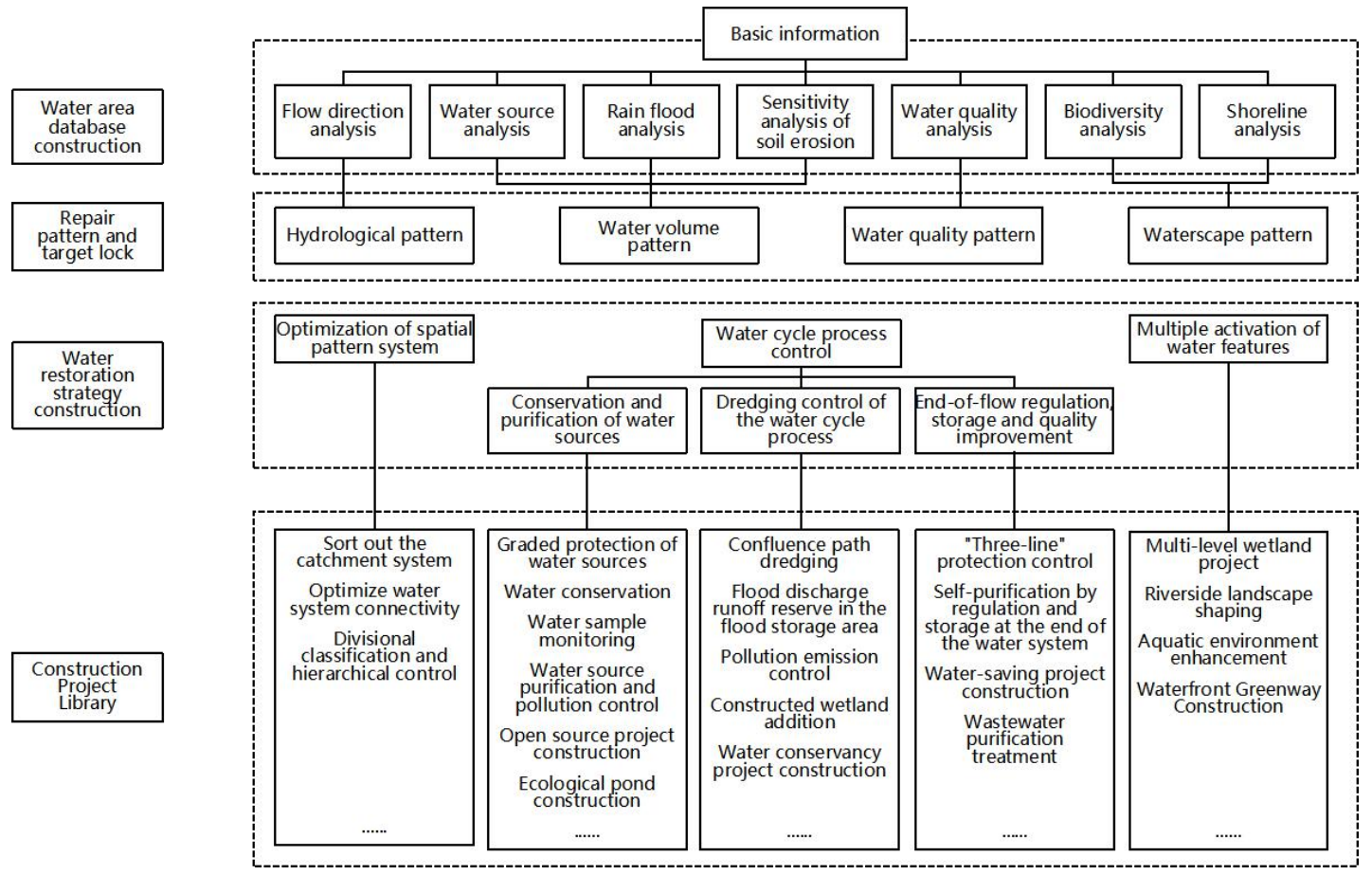

Figure 1. Regional Water System Restoration Framework under Ecological Wisdom. Source: Authors.

\section{Practice of water ecological restoration planning in Weiyuan County}

\subsection{Current situation and problems of water system}

Weiyuan County is endowed with natural resources and has a unique world-class dome and mountain topography. The county's river network is densely covered with twists and turns, and the rivers fluctuate and fall, which has the characteristics of a typical mountainous city water system. Taking Liangmu Mountain and Qingfengzhai as the watershed, the water system of Weiyuan County diverges from east to west, the east flank converges into the Weiyuan River, which belongs to the Tuojiang River system; the west flank converges into the Yuexi River, which is the Minjiang River system. Weiyuan County has obvious differences between the north and the south, The north is mainly the natural ecological space dominated by the dome and the mountain and the river water source area, and the south is mainly the urban construction area and agricultural production space (Figure 2). 
Evaluation of the overall spatial types of Weiyuan County

- The natural ecological space is mainly concentrated in the world-class dome in the northern part of the county.Urban development space is mainly concentrated in the central city and Lianjie Town, as well as other important urban spaces.

- The agricultural production space is mainly concentrated in the southern hilly area and scattered in the northern mountainous area.
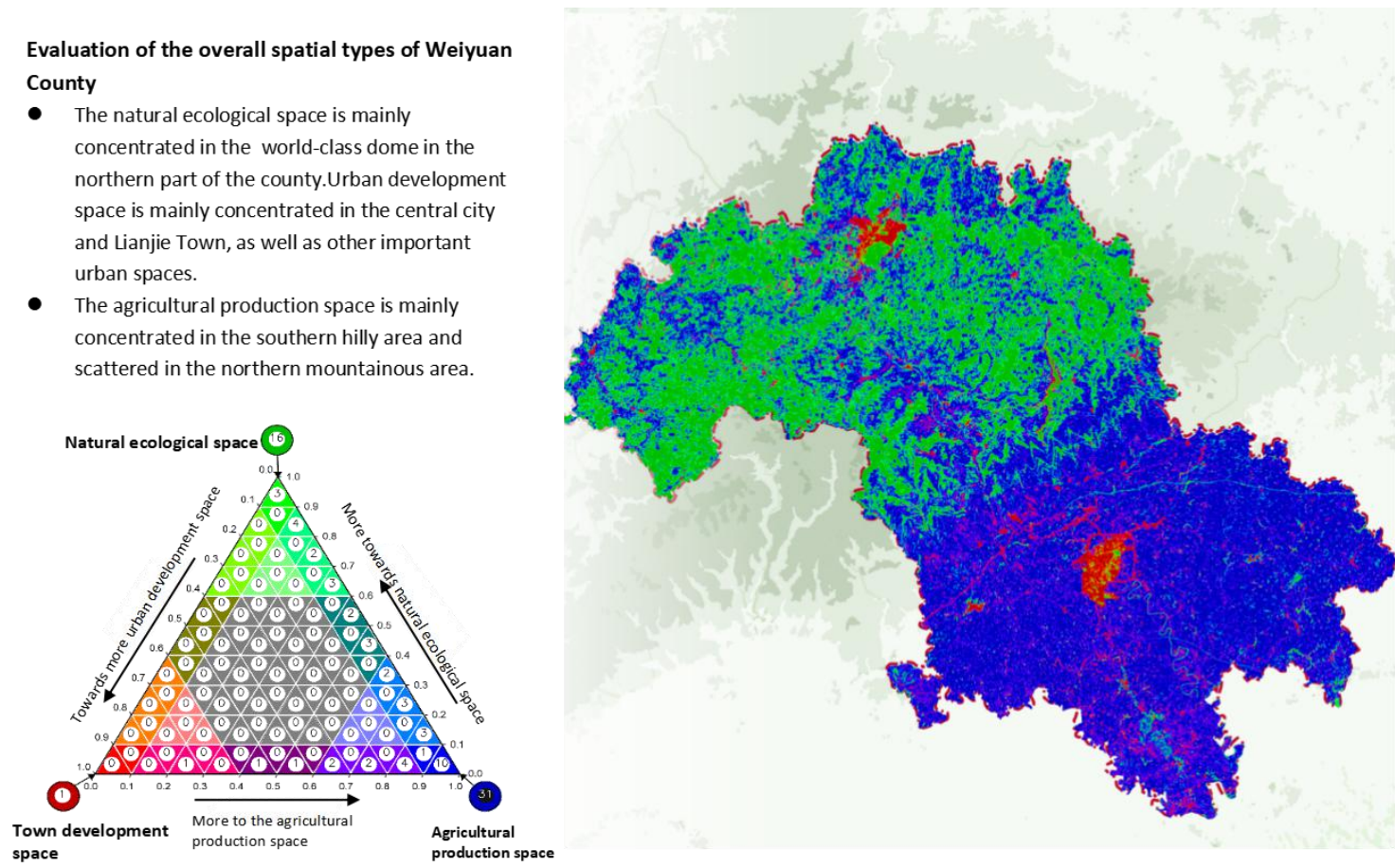

Figure 2. Evaluation of the overall spatial types of Weiyuan County. Source: Authors.

Based on the water base database, the river system in Weiyuan County has the following problems.

First, the hydrological pattern needs to be optimized. The analysis of river network line density and water source core density analysis shows that the river system is unevenly distributed between the north and the south. Reservoirs and tributaries are mostly distributed on the north side of the county. Although the river flow path is relatively abundant, it is generally cut off, which is not conducive to the region. The water ecological cycle also affects the rationality and stability of hydrology, water quality, water volume, and water features (Figure 3, Figure 4).

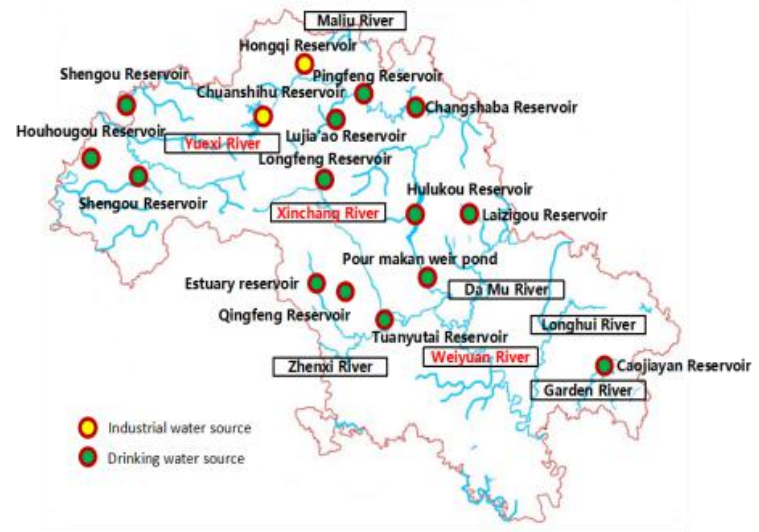

Figure 3. Water source analysis.

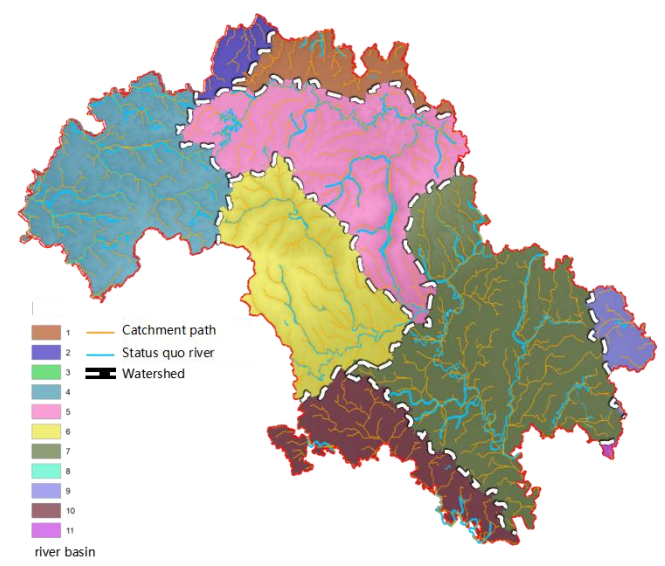

Figure 4. Flow direction analysis. Source:Authors.

Second, the water volume pattern needs to be repaired. There are a lot of rain and flood sensitive spaces in the western part of the county and the northern part of the main city, and the risk of rain and flood on both banks of the southern river is also relatively high. A large number of urban soil erosion points are formed around urban construction, roads, both sides of the water system, urban wasteland and other spaces(Figure 5). 


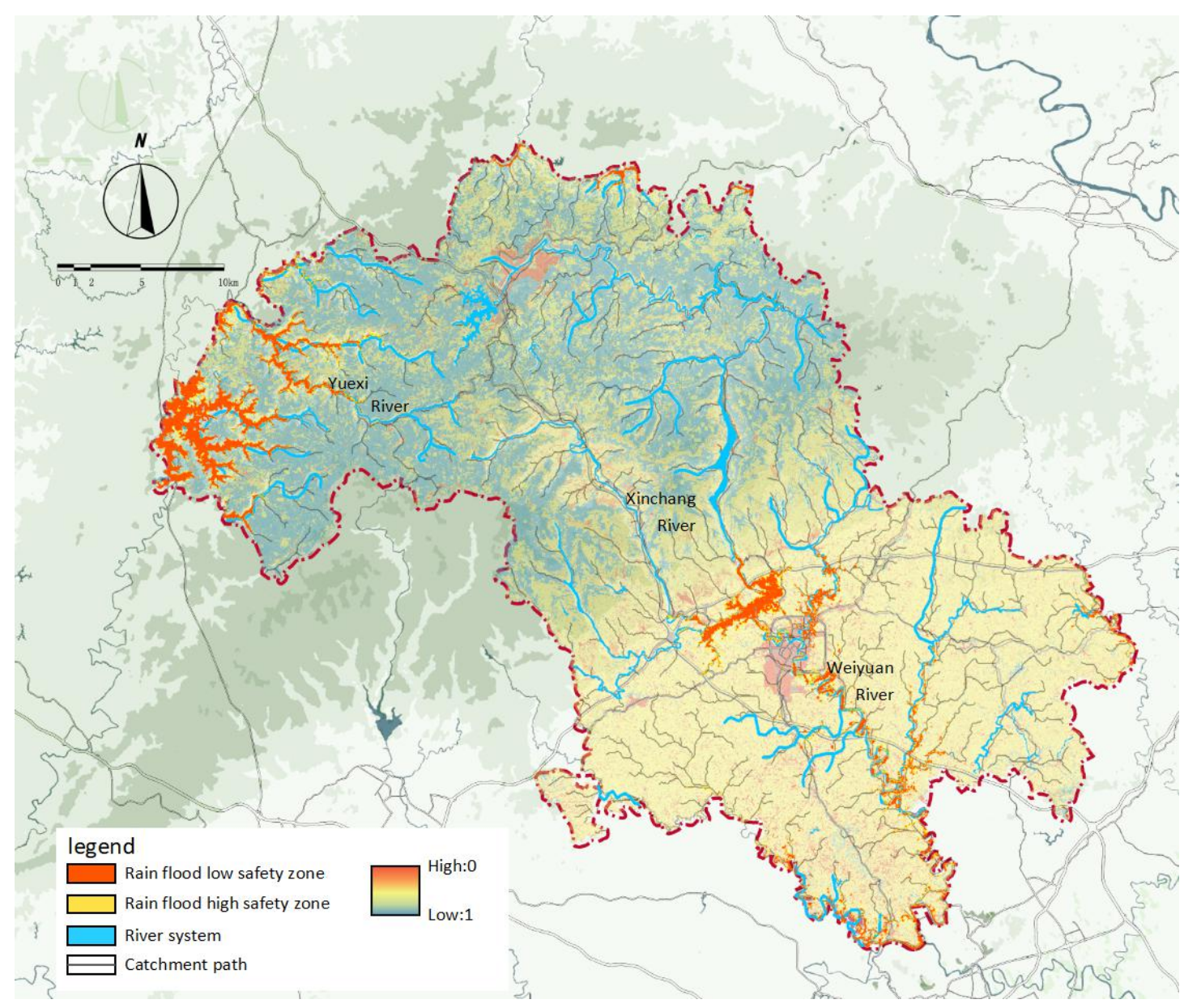

Figure 5. Sensitivity of soil erosion and flood safety pattern map of Weiyuan County. Source: Authors.

Third, the water quality pattern needs to be purified. The water quality of the river system is affected by urban construction and industrial and agricultural production, and it cannot purify itself within a period of time. The water quality in the upper reaches of the northern part of the county is relatively good, but some are also affected by surface and spot pollution, while the water quality in the south is relatively average. In addition, the space of water sources needs to be improved. Some water sources are close to pollution sources and lack sewage treatment facilities and garbage recycling facilities, Solid waste and domestic garbage directly enter the river and surrounding construction activities have an impact on the water quality of the water sources(Figure 6).

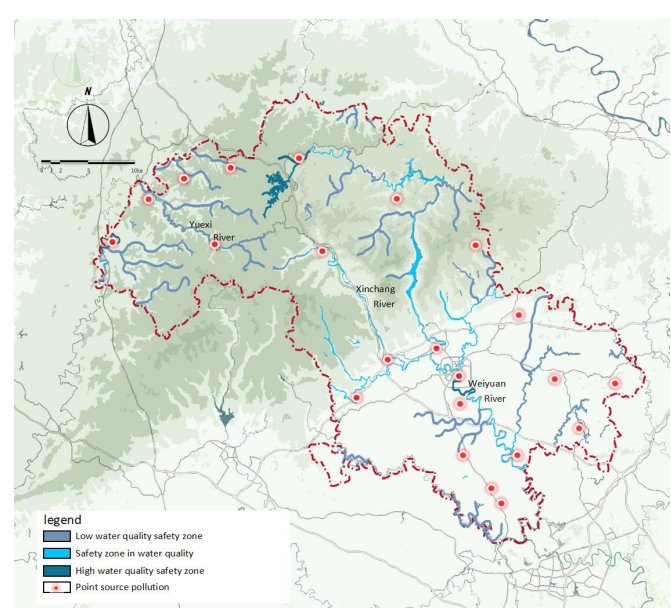

Figure 6. Water quality safety assessment map.

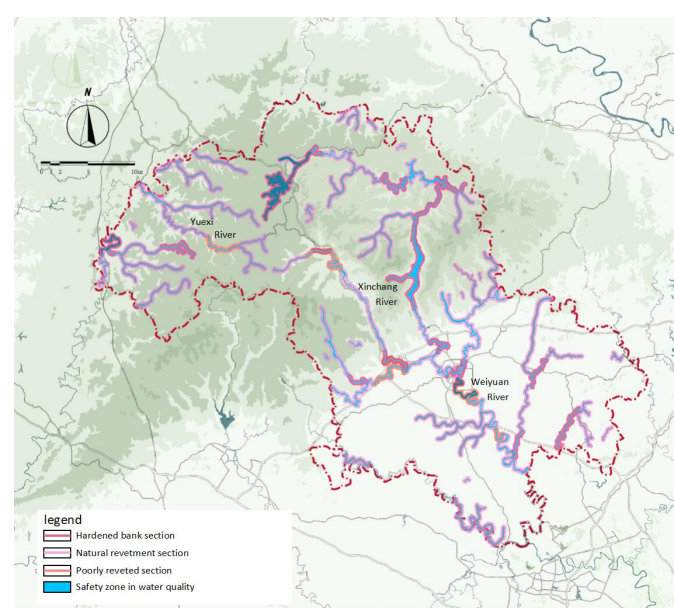

Figure 7.Shoreline assessment map. Source: Authors. 
Fourth, the characteristics of the landscape need to be brought into play. Natural shoreline are mixed with artificial shoreline. Natural shoreline are invaded by domestic waste from farmland, Artificial shoreline are severely channelized. The quality of the shoreline is generally poor. Among them, the qualityof productive shoreline are the worst. Need to increase the landscape characteristics to activate(Figure 7).

\subsection{Water system ecological restoration strategy}

\subsubsection{Ecological restoration pattern and goals}

The water system is the blood flowing in the city, showing its vivid life. The Weiyuan water system covers the whole area, connecting mountains, rivers, forests and fields, and plays the role of the regional urban ecological framework. Therefore, the ecological restoration of Weiyuan County takes water as the vein, relying on the relationship between mountains and rivers, to activate the five major spaces of the abandoned land,mountains, forests, fields and town.Weiyuan form an ecological landscape structure of "two areas, two veins, one screen, two rings, multiple corridors and multiple points", and build four ecological patterns: water system safety pattern, mountain forest habitat safety pattern, natural disaster risk safety control pattern, and multifunctional ecological landscape system pattern.

In terms of the target building, ecological restoration needs to correspond hydrology, water quality, water quantity, water features four elements form a target, a target to build relationships need to consider different spatial scales, usually considered from the macro, meso and micro three levels. Weiyuan County uses the concept of ecological wisdom to simulate the hydrological cycle process and set the overall goal of water body restoration as "connected and stable, diversified ecology, and coexistence between corridors and landscapes". And set up sub-target systems based on different spatial scales, namely, the macro level is" the north conserves the south and the purification, the green connection of urban and rural areas", the meso level is "the pattern optimization, the irrigation is orderly", and the micro level is "the integration of the scenery into the water and the clear water surface". The purpose is to build the Weiyuan water system into an ecological green belt that can promote urban and rural stability and maintain the balance of county habitats.

\subsubsection{Optimization of spatial pattern system}

The optimization of the pattern system is the basis for achieving "connected stability". The key to the optimization of the spatial pattern system is to establish a safe and smooth water catchment network mechanism. First, it is necessary to find the "breakpoints" of the water network caused by natural or human factors to dredge the whole water veins, and form an overall pattern of flexible adjustment of the water environment by moving the force of the whole region.Secondly, on the basis of system dredging, it is necessary to implement zoning, classification and fine control according to water characteristics. According to the water characteristics, Weiyuan can be divided into north water source conservation area and south water purification area.The northern reaches through enrichment planting vegetation, construction of water conservation zone soil desertification control, reduce soil erosion, increase water resources regulation and storage capacity to ensure High-quality and sufficient water sources. While in the south, clean and sufficient water resources are ensured through the construction of riverside greenways and wetland parks, and water quality purification (Figure 8). 


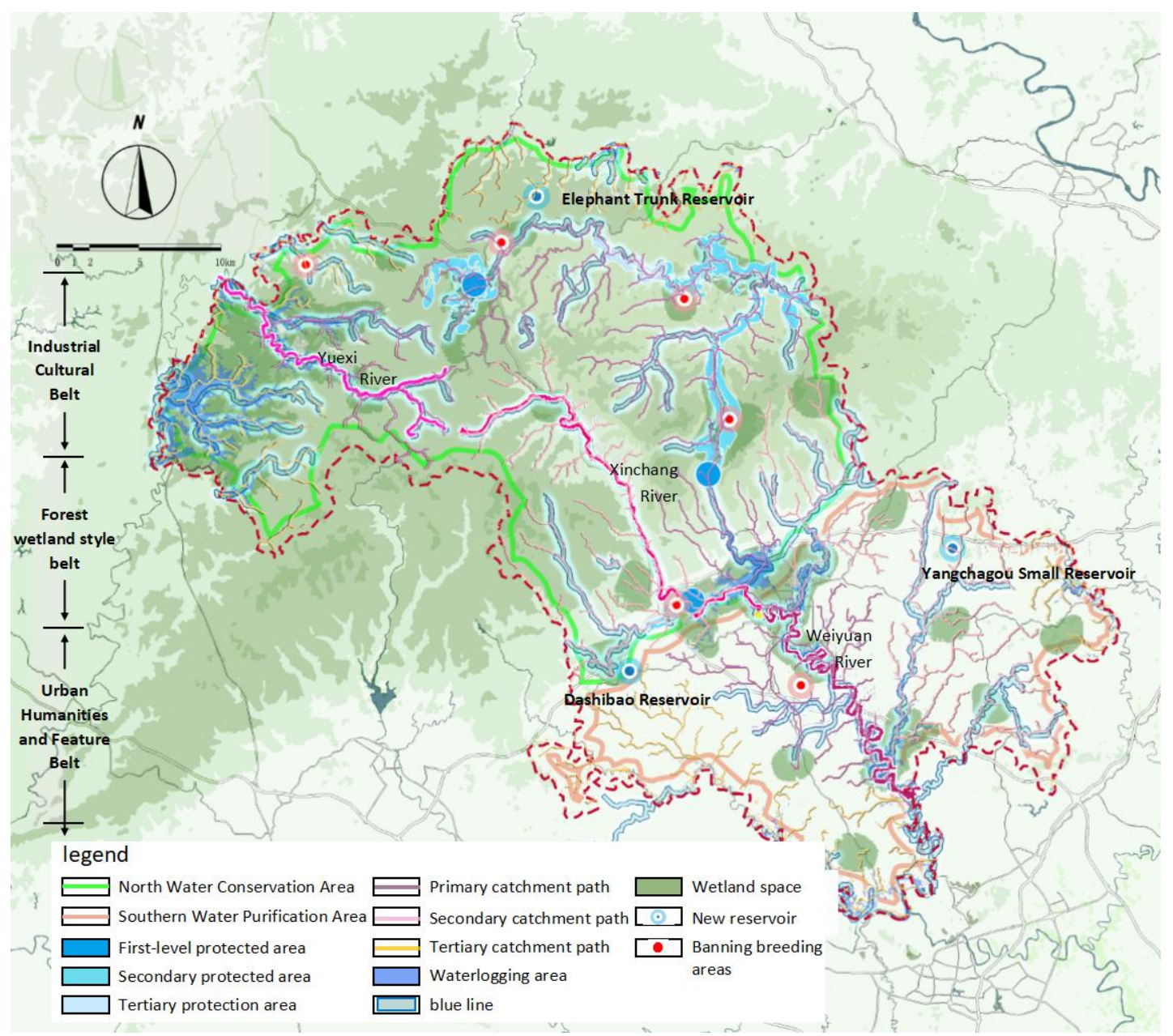

Figure 8. Guide map of water system restoration strategy. Source: Authors.

\subsubsection{Water cycle process control}

Learning the water cycle mechanism is the key to improving the rationality and stability of the water quality and quantity of existing river systems, and it is also an important measure for "ecological wisdom" to restore the water environment and enhance water resilience. The control of the water cycle mechanism should "reorganize" the river system on the basis of fully understanding the natural movement of the water system. Based on the natural hydrological pattern of production-sink-flow, the source, process, and end space are regarded as three important points for the study of water cycle mechanism.

(1) Conservation and purification of water sources

As an important runoff generation space, the source affect water quantity and quality and waterscape. Strengthening runoff space is the first step in the control of the water cycle process.In terms of ensuring the stability of water volume, determine the main drinking water source and divide the three-level protection area, set the corresponding protection scope and management and control requirements (Table 1), build a water source conservation area around the Strengthening runoff space, and conserve the water source in Weiyuan.Water body restoration under the concept of ecological wisdom should be resilient to urban natural disasters and self-regulate the water structure. Therefore, in addition to naturally formed water sources, corresponding open source measures are indispensable. Comprehensive utilization of rainwater and reclaimed water, through the construction of stagnant ponds to collect inverted rainwater for recycling, reducing the huge demand for fresh water. Fully consider the ornamental nature of traditional foundation pond technology, and turn the construction of stranded 
ponds into a "wetland bubble" dynamic water landscape, with different water levels to set up non-stop height difference and depth of plant landscapes to meet rainwater purification, storage, and infiltration , Stay and use, while bringing a good visual experience.

In terms of water quality safety, in addition to water source conservation, source purification and pollution control should be carried out to alleviate the pollution of lake water bodies caused by rainfall, build water pollution prevention measures, set up monitoring water intake points, and regularly take water samples to ensure that water quality standards are met.

(2) Dredging control of the water cycle process

The original river system was affected by urban construction, production and life in the flow process, and was trapped in the predicament of insufficient water and poor self-purification ability, and could not purify the water body in time. The river system not only does not play a role in adding points, but has a negative impact on the river's ecological service function, production output function and the quality of the surrounding environment, and aggravates the ecological vulnerability.

The improvement of regional water quality should first consider sufficient water balance to form a healthy water cycle process to enhance the self-purification ability of water circulation. The water balance in the process should clear the confluence path. According to the characteristics of topography and catchment zones, determine rainwater drainage zones and paths, protect and repair natural runoff channels, dredge and extend the "breakpoints" of confluence paths, and rationally control and organize surface runoff to enhance river drainage and flood discharge capacity. For urban built-up areas, ecological water catchment pathways can be constructed by planting grass ditches and other methods, and water catchment channels can be preset along the catchment pathways (Figure 8).

The reserved flood storage area and the addition of artificial wetland affect the improvement of water quality and the stability of the total water body.Identify and control the rainstorm inundation area of each basin based on the rainwater safety pattern, and select the area inundated by a 24 -hour rainstorm once in 10 years, reserve the area as the waterlogging storage area.To ensure the safety of life and property of residents, urban construction is not allowed within the flood storage area as an area prone to inundation, and the constructed area should be gradually moved out.Divide three-level runoff for flood discharge and waterlogging drainage, use river dredging and ecological pollution to protect runoff, dredge the water cycle, and strengthen the self-cleaning ability of water bodies.Combining the flood storage area and the confluence path to create a green space, using low-impact development facilities such as rainwater wetlands, wet ponds, and regulating ponds to extend the residence time of rainwater on the ground, enhance soil water content to achieve water replenishment during dry seasons, and the construction of rainwater gardens can also form a good Landscape effect.

The water cycle is continuously affected by industrial pollution, surface pollution and point pollution, which intensifies ecological vulnerability. The source of water pollution in Weiyuan County is due to the agricultural non-point source pollution in the process. For this, the livestock breeding pollution should be strictly controlled. , Ban the livestock breeding in the prohibited areas, and timely deal with the pollution of the livestock breeding outside the prohibited areas (Figure 8). Second, the application of chemical fertilizers and pesticides should be controlled, and organic fertilizers should be implemented to replace chemical fertilizers to effectively reduce non-point source pollution of agricultural products.

(3)End-of-flow regulation, storage and quality improvement

The "three-line" protection and control method is adopted, and different control requirements are divided according to the level of the river, including the river center line, the river blue line and the river protection range line.The "three-line" division method reserves a certain area outside the blue line of the river as an ecological green corridor, which is an important place for water environment improvement, 
ecological restoration, landscape construction, and flood control and drainage.The planning is combined with the classification of river systems in Weiyuan County to form the first, second, and third "three-line" control standards (Table 2), and the "wetland bubble" landscape is built within the river protection scope to build a park wetland, improve the quality of water and create a waterscape.

Table 1. Water source classification management and control requirements.

\begin{tabular}{l|l}
\hline Water source & Scope of protection zone \\
\hline First-level protected area & $\begin{array}{l}\text { Water and land areas within a radius of } 500 \text { meters with the water } \\
\text { intake point as the center }\end{array}$ \\
\hline second level & $\begin{array}{l}\text { Water areas other than the first-level protection zone and land areas } \\
\text { within } 200 \text { meters above the normal water storage line, as well as } \\
\text { water areas up to } 2500 \text { meters from the entrance of the river flowing } \\
\text { into the reservoir (including all water areas of Tianxing Reservoir) and } \\
\text { land areas within } 200 \text { meters on both sides of the river bank }\end{array}$ \\
\hline Quasi-protected area & $\begin{array}{l}\text { The water area up to } 500 \text { meters from the river in the secondary } \\
\text { protection zone and the land area with a depth of } 200 \text { meters on } \\
\text { both sides of the river bank }\end{array}$ \\
\hline
\end{tabular}

Table 2. Weiyuan County River System "Three-line" Protection Control.

\begin{tabular}{l|l|l|l}
\hline \multicolumn{2}{l|}{ River grade } & River width control & Protection range line \\
\hline \multirow{2}{*}{ First-level } & Weiyuan River & Central city area $50-100 \mathrm{~m}$ & $\leq 100 \mathrm{~m}$ \\
\cline { 2 - 4 } & Yuexi River & -- & $\leq 30 \mathrm{~m}$ \\
\cline { 2 - 4 } & Damu River & Central city area $50-150 \mathrm{~m}$ & $\leq 20 \mathrm{~m}$ \\
\hline Second-level & $\begin{array}{l}\text { Longhui River, Wulong River, } \\
\text { Zhenxi River,Xinchang River }\end{array}$ & -- & $\leq 15 \mathrm{~m}$ \\
\hline third-leve & -- & -- & $\leq 10 \mathrm{~m}$ \\
\hline
\end{tabular}

\subsubsection{Multiple activation of waterscape}

The characteristics of landscape pattern are related to water quantity, water quality, openness of water surface, riverside vegetation, and riparian type.To activate the waterscape at the county level, we must first increase the multi-level wetland space, and combine the storm flood safety pattern, sewage treatment plant, and key reservoir planning to construct three levels of wetland space, which are rain flood wetland, reservoir wetland, and ecological pollution control wetland.

Relying on the river orientation, spatial distribution characteristics of Weiyuan River and Yuexi River, and the reservoirs along the line, a total of 20 wetland spatial systems have been formed, including " 2 large, 3 medium and 15 small"(Figure 17).Combining the spatial pattern of wetland, greenway construction will be carried out in riverside areas with superior landscape resources and good traffic conditions, and a three-level riverside recreational ecological greenway system will be constructed. The independent parks, wetlands, swamps and other habitats are organically connected through greenways, and the quality of urban and rural spaces is improved by relying on the natural environment. According to the nature of land use along the shoreline, three river style belts will be created for the Yuexi River Industrial Culture, 
Xinchang River Forest Wetland, and Weiyuan River Urban Humanities, and three levels of aquatic, watermarginal, and interbank plant systems are configured (Figure 9).

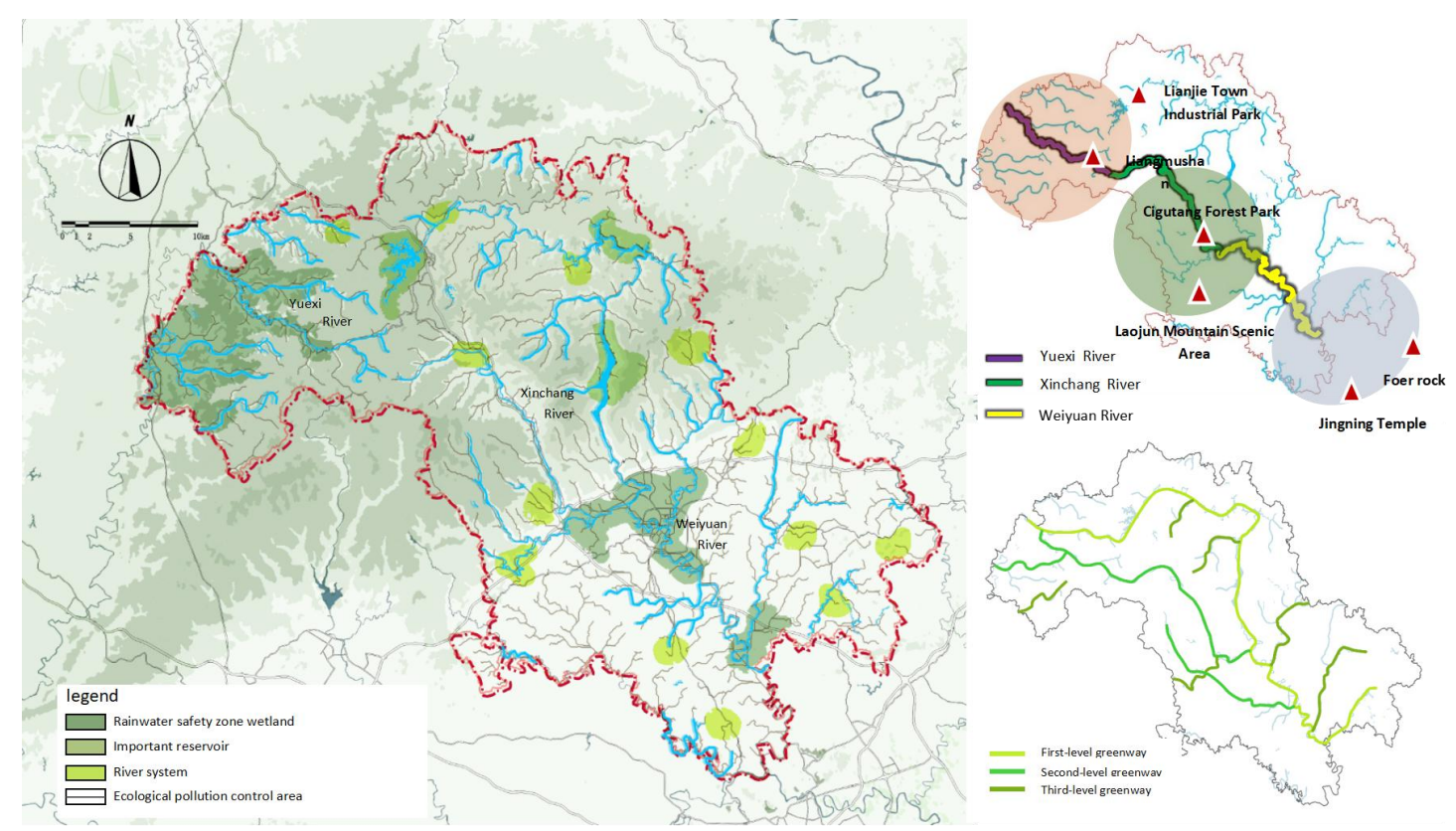

Figure 9. Wetland space system diagram, Riverfront Greenway system map, Schematic diagram of river style zone.Source: Authors.

\section{Conclusion}

Due to the complex impact of urban construction activities on river systems, not only the quality of urban inland rivers has dropped sharply, but also the quality of river systems outside of urban built-up areas has also gradually deteriorated. As a complex organism, various parts of the region are highly correlated, resulting in unfavorable consequences. Therefore, it is very necessary to discuss how to maintain the ecological characteristics of rivers from degrading for a long time at the regional level. Ecological wisdom combines the core features of wisdom with the core ecological features, emphasizing the restoration of original ecological functions and the simulation of ecological processes. This article takes Weiyuan County as an example. This article focuses on Weiyuan County and introduces the concept of ecological wisdom, emphasizing the protection and restoration of water cycle mechanisms and learning simulation. , Constructed a set of water body data construction, pattern target lock, water body restoration strategy construction, and construction project database to determine the entire water body restoration framework. However, as far as the current stage is concerned, the simulation of the water cycle mechanism is currently carried out from three aspects: the source, the process, and the end. The understanding is relatively shallow, and the next stage of discussion and in-depth research is needed. 


\section{References}

Chen, L.F. Exploration of the water system planning path of mountain cities under the theory of sponge city[J]. Urban Planning, 2016, 40(03): 95-102.

Sun, Y.X, Tang Xiaoxiang. Analysis of the ecological wisdom in the traditional settlements in the Guangfu area of Lingnan[J]. Huazhong Architecture, 2012, 30(10): 164-168.

Danilo Palazzo. Urban Ecological Design A Design Process of Recycling Sites[M]. Yilin Publishing House, 2018.

Li H, Yang P.f, Zhang ZX, et al. Planning strategy for improving spatial resilience of mountainous urban water system from the perspective of "design ecology"[J]. Planner, 2019,35(15):53-59.

Lao B.I, Cao F. Research on ecological restoration of rivers in arid areas from the perspective of ecological civilization: Taking the ecological restoration of Yunzhong River in Xinzhou City as an example[J]. Chinese Landscape Architecture, 2019,35(11):41-46 .

Zhou X.Y, Zheng D.Y. Evaluation of ecological security pattern of Wuhan city circle[J]. Urban Planning, 2018,42(12):132-140.

Zhao K, Xia Q.Q. The ecological planning method of urban water space system with small watershed as a unit_- Taking Dazhou Economic Development Zone in the small watershed of Zhouhe as an example[J]. Chinese Landscape Architecture, 2015, 31(01):41-45.

Meng X.Y, Shi C.X, Liu SY, et al. CMADS data set and its driving role in the hydrological model of a river basin: Taking the Heihe River Basin as an example [J]. People's Pearl River, 2016, 37(07):1-19.

$\mathrm{Li} \mathrm{H}$, Yang P.F. Deduction of planning strategy for urban inland river space ecologicalization and stability maintenance[J]. Urban Planning, 2018, 42(05): 56-62.

Shen, Q.J. Ecological restoration in the "Double Urban Repair"[J]. Environmental Economy, 2017(15): 1214.

Wang W.J, Huang D.M. Research progress of river ecological restoration at home and abroad[J]. Journal of Water Ecology, 2012, 33(04): 142-146.

Wang Y.C, Huang J.D. The logic and strategy of mountain ecological restoration in Taiyuan City guided by ecological wisdom[J]. Chinese Garden, 2019, 35(07): 56-60. 